\title{
PISA 2012 verilerine göre matematik okuryazarlığının lojistik regresyon ile kestirilmesi ${ }^{\star}$
}

\author{
Estimation on the mathematics literacy with logistic regression according to \\ PISA 2012 data
}

\author{
Ceren MUTLUER ${ }^{\star \star}$ \\ Serap BÜYÜKKIDIK ${ }^{* * *}$
}

\begin{abstract}
Öz
Bu çalışmada Uluslararası Öğrenci Değerlendirme Programı olarak bilinen ve 2000 yılından bu yana her üç yılda bir tekrarlanan PISA araştırmasının 2012 Türkiye verileri kullanılarak öğrencilerin matematik okuryazarlığının, seçilmiş olan matematik dersini dört gözle bekleme, matematik ilgisi, matematik öz algılama / hızlı öğrenme, azim - çabuk pes etme, matematik ile ilgili okuma yapma, matematikten zevk alma, anne ve baba eğitim durumu değişkenleri ile lojistik regresyon tekniği kullanılarak hangi doğruluk düzeyinde sınıflayabildiğinin belirlenmesi amaçlanmıştır. Yordayıcı korelasyonel desen kullanılarak yapılan araştırmanın çalışma grubunu 596 birey oluşturmaktadır. Verilerin analizi sonucunda matematik okuryazarlığının sınıflandırılmasında anne eğitim düzeyi, baba eğitim düzeyi, matematikten zevk alma, matematik öz algılama/hızlı öğrenme, azim- çabuk pes etme bağımsız değişkenlerin anlamlı etkisi olduğu görülmektedir. Matematik ile ilgili okuma yapıp-yapmama ve matematik ilgisi düzeyi matematik okuryazarlı̆̆ı üzerinde anlamlı etkiye sahip değildir. Elde edilen lojistik regresyon modelinde gözlemlerin doğru sınıflandırma oranlarının \%85,2 olduğu görülmektedir. Araştırma bulgularına göre matematik okuryazarlığında başarılı olan öğrencilerin \%94,9’u, başarılı olmayan öğrencilerin ise $\% 54,9^{\prime} \mathrm{u}$ doğru olarak tahmin edilmiştir.
\end{abstract}

Anahtar Kelimeler: Matematik okuryazarlığı, PISA, lojistik regresyon

\footnotetext{
Abstract

The aim of this study is to determine the effectiveness of the variables on classification of students' math literacy, mathematical interest, looking forward to mathematic lessons, self detection/fast

* Bu çalışma EPOD 2014'de sözlü bildiri olarak sunulmuştur.

** Öğr. Gör., Abant İzzet Baysal Üni., Eğitim Fak., Eğitim Bilimleri, Eğitimde Ölçme ve Değerlendirme,

*** Arş. Gör., Gazi Üni., Eğitim Fak., Eğitim Bilimleri, Eğitimde Ölçme ve Değerlendirme,
} cmutluer@yandex.com. sbuyukkidik@gmail.com. 
learning, being determined- easily giving up, reading about mathematics, enjoying mathematics, education level of mother and father by logistic regression by analyzing the 2012 Turkey scores of PISA, known as the International Student Assessment Program, which has been repeated every three years since 2000. The sampling of the research which is in the model of survey constitutes 4848 individuals. From the results of the analysis of the data, in the classification of mathematics literacy, the independent variables of looking forward to the lesson, the level of education for mother and father, appreciation in mathematics, self-detection in mathematics, quickly learning, perseverance, quickly giving up had a significant effect. Reading about mathematics and the level of interest for mathematics didn't have a significant effect on mathematics literacy. It is observed that the percentage of correct classification in logistic regression model was $\% 85,2$. According to the results of the research $\% 94,9$ of the students who were successful mathematics literacy and $\% 54,9$ of the students who are unsuccessful were correctly estimated.

Keywords: Mathematics literacy, PISA, logistic regression

\section{Giriş}

Değişen 2004 öğretim programı ile öğrencileri daha fazla düşünen, öğrendiklerini daha çok hayata uygulayan, bol sorular soran bir kişi haline gelmesi ve çözüm yollarının keşfinde öğrencilerin uygun yeterliğe ulaşması hedeflenmiştir. Bu amaçlar diğer ülkelerde de benzerlikler göstermektedir. Artık öğrencinin ne kadar bilgi düzeyine sahip olmasından ziyade, bu bilgiyi günlük yaşama ne kadar aktarabildiği önem taşımaktadır. Ülkelerin kendi eğitim sisteminin çıktıları olarak belirledikleri değişen öğrenci davranışlarını karşılaştırmak ve diğer ülkeler arasındaki yerini görmek için Uluslararası Matematik ve Fen Eğilimleri Araştırması- TIMSS (Trends in International Mathematics and Science Study), Uluslararası Öğrenci Değerlendirme Programı- PISA (Programme for International Student Assessment), Uluslararası Okuma Becerilerinde Gelişim Projesi-PIRLS (Progress in International Reading Literacy Study) gibi geniş ölçekli testler uygulanmaktadır. Bu sınavlardan PISA'da öğrencilerin gerçek hayatta karşılaşabilecekleri fen problemlerinde, matematik problemlerinde ve sınavlarda açık bir şekilde ölçülmeden ölçülmeye çalışllan okuma becerisinde ne kadar başarılı olacakları araştırılmaktadır.

MEB (2013) PISA ön raporuna göre,

(...) PISA, Ekonomik İşbirliği ve Kalkınma Teşkilatı- OECD (Organisation for Economic Co-Operation and Development) tarafından düzenlenen dünyanın en kapsamlı eğitim araştırmalarından biridir. 2000 yılından itibaren üç yılda bir yapılan bu araştırmayla OECD üyesi ülkeler ve diğer katılımcı ülkelerdeki (dünya ekonomisinin yaklaşık olarak \%90’i) 15 yaş grubu öğrencilerin modern toplumda yerlerini alabilmeleri için gereken temel bilgi ve becerilere ne ölçüde sahip oldukları değerlendirilmektedir (s.9).

OECD tarafından düzenlenen PISA, ülkelerin sadece okul içi öğrenci profillerini ortaya çıkaran bir değerlendirme projesi olmaktan çok öğrendiklerini okulda ve okul dışı yaşamlarında 
kullanabilme yeterliklerinin; karşılaşacakları yeni durumları anlamak, sorunları çözmek, bilmedikleri konularda tahminde bulunmak ve muhakeme yapabilmek için bilgi ve becerilerinden ne ölçüde yararlanabildiklerinin belirlenmesi hedeflenmektedir.

Her bir periyodu; matematik, fen ve okuma beceri alanlarından biri olan ve üç yılda bir döngüsel olarak tekrar eden çalışma, 2012 yılında matematik alanında gerçekleştirilmiştir. 2012 yılı sonuçlarına bakıldığında ülkemiz ortalamalarının her üç alanda da OECD ortalamalarının altında kaldığı görülmektedir. PISA 2012'de Matematik okuryazarlığı, çeşitli bağlamlarda bireyin formüle etme, matematiği kullanma ve yorumlama kapasitesi olarak tanımlanmaktadır. Bu kapasite matematiksel olarak akıl yürütmeyi; bir olguyu açıklamak ve tahmin edebilmek için matematiksel kavramları, işlemleri ve araçları kullanmayı içerir. Matematik okuryazarlı̆̆ı bireyin; dünyada matematiğin oynadığı rolü fark etmesine ve anlamasına, sağlam temellere dayanan yargılara ulaşmasına, yapıcı, ilgili, duyarlı bir vatandaş olarak kendi ihtiyaçlarını karşılayabilecek şekilde matematiği kullanmasına yardımcı olmaktadır (MEB, 2013).

Matematiksel içeriğe göre maddeler incelendiğinde yapılan sınıflandırmanın matematiğin gelişiminde rol oynayan olgular ile okul müfredatlarındaki ana temalar çerçevesinde yapıldı̆̆ görülmektedir. Matematiksel içerik dört farklı kategoride ele alınmıştır. Bunlar; sayısal olayları veya durumları, sayısal ilişkileri ve örüntüleri içeren nicelik (quantity); uzamsal ve geometrik çalışmaları içeren uzay ve şekil (space and shape); değişkenler arasındaki ilişkileri ve bunların sunulması sırasında (denklem kullanımındaki gibi) kullanılması gereken cebirsel bilgi ve anlayışı içeren değişim ve ilişkiler (change and relationships), olasılıkları, istatistiksel olayları ve durumları içeren belirsizlik (uncertainty) kategorileridir (MEB, 2015).

Araştırmacılar bilginin günlük yaşama aktarılmasını içeren PISA' ya büyük bir ilgi göstermiş ve birçok araştırma yapmışlardır (Ada, 2015; Anıl, 2008, 2009; Aydın, Erdağ ve Taş, 2009; Balım, Evrekli, İnel, ve Deniş, 2009; Berberoğlu ve Kalender, 2005; Ceylan, 2009; Chiu ve Xihua, 2008; Çiftçi, 2006; Gürsakal, 2012; Koğar, 2015; Satıc1, 2008; Shin, Lee ve Kim, 2009; Uysal, 2015; Yılmaz, 2006; Zhang ve Liu, 2016). Berberoğlu ve Kalender (2005) PISA 2003 sonuçlarından elde edilen bölgesel ve okul türleri arasındaki farklılıkları analiz etmişlerdir. Bölgesel farklılıklardan çok okul türleri arasındaki farklılıkların ciddi boyutta olduğunu bulmuşlardır. Anıl (2008) PISA 2006 matematik okuryazarlığıyla ilişkili olduğu düşünülen değişkenleri yapısal eşitlik modellemesi ile incelemiş ve kurulan yapısal eşitlik modeli incelendiğinde, öğrencilerin matematik başarısını en iyi tahmin eden değişkenin "zaman” olduğu tespit edilmiştir. Matematik başarısını belirleyen ikinci faktör "eğitim" değişkeni olarak belirlenmiştir. Bu değişkenin, anne-babanın eğitim düzeyi ve evdeki kitap sayısı maddelerinden oluştuğu ve öğrencilerin matematik başarısına olumlu katkı sağladığı belirtilmiştir. Anıl (2009) yaptığı araştırmada, Uluslararası Öğrenci Başarılarını Değerlendirme Programı 2006 kapsamında, Türkiye’de 15 yaş grubu öğrencilerin fen bilimleri başarılarını etkileyen faktörlerin neler olduğunu belirlemeyi amaçlamıştır. Verilerin analizinde, fen bilimleri başarısını etkileyen faktörleri belirlemek için öncelikle öğrenci anketinde yer alan sorular, temel bileşenler analizinden yararlanılarak belirlenmiştir. Araştırmanın alt problemlerinde, belirlenen yordayıcı değişkenlerin 15 yaş grubu öğrencilerin fen başarısını yordama gücünü belirlemek için aşamalı çoklu regresyon analizinden yararlanılmış, frekans ve yüzde değerlerine yer verilmiştir. 
Araştırmadan elde edilen bulgularda, Türkiye’deki 15 yaş grubu öğrencilerin fen bilimleri başarısını en çok yordayan değişkenin, "babanın eğitim durumu” olduğu belirlenmiştir. Aydın, Erdağ ve Taş (2009) yaptığı araştırmada, 2003 - 2006 PISA okuma becerileri sonuçlarını; Türkiye ve en başarılı beş OECD ülkesinin (Finlandiya, Kanada, Japonya,Yeni Zelanda ve Avustralya) sınav sonuçları ve başarı veya başarısızlı̆̆a neden olabilecek bazı değişkenlerle (sosyo-ekonomik ve sosyokültürel) karşılaştırmalı olarak incelemişlerdir. Balım ve diğerleri (2009) PISA 2006'daki verilerle bilgi ve iletişim teknolojilerinin kullanımının, öğrencilerin fen yeterlilik düzeylerinde anlamlı bir farklılığa neden olduğunu belirlemişlerdir. Ceylan (2009) Türkiye'de bulunan, yüksek performans göstermiş okullar ile düşük performans göstermiş okullar arasındaki farklılıkları, PISA 2006 öğrenci anketinden elde edilen beş örtük değişken temelinde ayırma analiziyle incelemiş ve elde edilen bulgular neticesinde okulların dört örtük değişkene (Öğrenci merkezli etkinliklerin (OME), sosyo-ekonomik düzeyleri (SED) ve fene yönelik tutumları (FYT), günlük yaşamları ile feni ilintilendirebilmeleri) göre anlamlı bir şekilde farklılaştığını göstermiştir. Shin, Lee ve Kim (2009) PISA 2003 verileriyle Japon, Koreli ve Amerikalı öğrencilerin öğrenci ve okul düzeyi faktörüne göre Hiyerarşik Linear Modelleme yöntemiyle matematik ilgisi, rekabetçi öğrenme tercihleri, araçsal güdülenme öğrenci düzeyinde yordayıcılarla ve öğrenci-öğretmen ilişkisi, okul disiplin iklimi okul düzeyinde değişkenlerinin matematik başarıları ile olan ilişkisi karşılaştırılmıştır. Bu üç ülkede öğrenci ve okul düzeyinde yordayıcıların ve matematik başarısının arasındaki ilişkilerin farklı örüntüler sergilediği görülmüştür. Gürsakal (2012) araştırmasında lojistik regresyon kullanarak öğrencilerin fen ve matematik okuryazarlıkları ile okuma becerileri puanlarını etkileyen faktörleri tespit etmeye çalışmıştır. Analiz bulguları; öğrencilerin başarı düzeylerinin cinsiyet, okula başlama yaşı, anne babanın eğitim düzeyi gibi değişkenler açısından farklılık gösterdiğini ortaya koymuştur. Koğar (2015) PISA 2012 matematik okuryazarlığına etki eden dolaylı ve doğrudan etkileri ortaya koymayı amaçladığı çalışmasında cinsiyet, ekonomik, matematik öğrenmek için harcanan zaman ve sosyo-kültürel durum indeksi bağımsız değişkenlerinin, matematik okuryazarlığı üzerinde anlamlı bir etkisi olduğu sonucuna varmıştır.

Tüm bu çalışmalar incelendiğinde PISA 2012 verilerinde matematik öz algılama hızlı öğrenme, azim- çabuk pes etme, matematik ile ilgili okuma yapma, matematikten zevk alma, matematiğe karşı ilgi, azim-çabuk pes etme, anne ve baba eğitim durumu değişkenlerinin ele alınıp hangi doğruluk düzeyinde matematik okuryazarlığını sınıflayabildiğini araştıran bir çalışmaya rastlanmamıştır.

Araştırmanın odağ 1 olarak seçtiğimiz matematik okuryazarlığı gibi pek çok odak noktası etrafında geliştirilen çalışmalar için herkesin kullanımına açık olan OECD uzantılı PISA veri tabanı içerisinde yer alan değişkenler ve veri sayısı dikkate alındığında bu araştırmanın birçok istatistiksel analiz için oldukça elverişli olduğunu söylemek mümkündür.

Araştırma kapsamında öğrenci anketinden yararlanarak matematik ilgisi, matematik öz algılama hızlı öğrenme, azim- çabuk pes etme, matematik ile ilgili okuma yapma, matematikten zevk alma, matematiğe karşı ilgi, matematiköz algılama/hızlı öğrenme, azim-çabuk pes etme, anne ve baba eğitim durumu değişkenlerinin matematik okuryazarlığını etkilediği düşünülmüştür. Bunun için matematik okuryazarlığını etkileyen bahsedilen faktörler lojistik regresyon yöntemi ile analiz edilmiştir. 
Araştırmanın amacı matematik ilgisi, matematik öz algılama /hızlı öğrenme, azim-çabuk pes etme, matematik ile ilgili okuma yapma, matematikten zevk alma, matematik öz algılama/hızlı öğrenme, azim-çabuk pes etme, okuldan sonra matematik için ekstra zaman ayırma, anne ve baba eğitim durumuna göre öğrencilerin PISA 2012 verilerine göre başarı durumlarını hangi doğruluk düzeyinde sınıflayabildiğini lojistik regresyon yöntemi kullanarak belirlemektir.

\section{Yöntem}

\section{Araştırmanın Deseni}

Araştırmada, Türkiyede 15 yaş grubu öğrencilere Uluslararası Öğrenci Başarılarını Değerlendirme Programı (PISA) kapsamında uygulanan öğrenci anket sonuçlarından belirlenen yordayıcı değişkenler ile matematik başarısı arasındaki birlikte değişim incelendiğinden, araştırma türü, ilişskisel bir araştırmadır.

Büyüköztürk, Kılıç Çakmak, Akgün, Karadeniz ve Demirel (2013)'e göre,

(...) korelasyonel araştırma, iki ya da daha çok değişken arasındaki ilişkinin herhangi bir şekilde bu değişkenlere müdahale edilmeden incelendiği araştırmalardır (s.184).

Araştırma kapsamında yordayıcı korelasyonel desen de kullanılmıştır. Yordayıcı korelasyon araştırmalarında değişkenler arasındaki ilişkiler incelenerek değişkenlerin birinden yola çıkarak diğeri yordanmaya çalışılır. Yordama işleminde bir değişkenin bilinen bir değerinden yola çıkarak diğer değişkenin bilinmeyen değeri bilinmeye çalışılır. Bu değişkenlerden, yordama işlemi yapılacak olan değeri bilinen değişkene yordanan değişken, değeri bilinecek değişkene ise ölçüt değişken denir (Fraenkel, Wallen ve Hyun,2012). Bu çalışmada bağımsız değişkenler matematik dersini dört gözle bekleme, matematik ilgisi, matematik öz algılama hızlı öğrenme, azim- çabuk pes etme, matematik ile ilgili okuma yapma, matematikten zevk alma, anne ve baba eğitim durumudur. Bu değişkenler yordayıcı korelasyonel desende yordayıcı değişkenler olarak edilmektedir. Araştırmada belirlenen bağımlı değişken ise matematik okuryazarlı̆̆ıdır. Matematik okuryazarlığı değişkeni, PISA 2012 puan ortalamasının (494) üstünde puan alanların "başarılı" bu değerin altında puan alan kişiler "başarısız" olarak iki kategoriye ayrılmıştır.

\section{Araştırma Grubu}

Eğitimdeki performansla ilgili yapılan uluslararası karşılaştırmaların geçerli olabilmesi için örneklem, belirli bir yaş grubuna göre belirlenmektedir. PISA öğrenci evreni, okul türüne bakılmaksızın okullarda öğrenim gören, değerlendirmenin yapılacağı tarih itibarıyla yaşları 15 yıl 3 ay ve 16 yıl 2 ay arasında değişen, en az altı yıllık örgün eğitimi tamamlamış öğrencilerden oluşmaktadır (MEB, 2013).

PISA 2012 uygulamasına, 65 ülkeden 15 yaşında yaklaşık 28 milyon öğrenciyi temsilen 510 bin civarında öğrenci katılmıştır. PISA 2012 çalışmasına Türkiye’den 4848 öğrenci katılmıştır. 
Bu öğrencilerin 2370'ini kızlar oluştururken, 2478'ini erkekler oluşturmaktadır. PISA matematik ortalamasının (494) -1 standart sapmanın altında kalanlar başarısız, ortalamanın +1 standart sapma üstünde kalanlara başarılı olarak iki kategoriye ayrılarak 15 yaşındaki 596 öğrenciden elde edilen puanlarla lojistik regresyon analizi yapılmıştır.

\section{Verilerin Toplanması}

Araştırmada veri toplama aracı olarak PISA 2012 kapsamında öğrencilere uygulanan matematik okuryazarlığını ölçen bilişsel test ve öğrenci anketi kullanılmıştır.

\section{Verilerin Analizi}

Bağımlı ve bağımsız değişken ayrımının yapıldığı çok değişkenli bir modelde, bağımlı değişken sınıflama ölçekli bir değişken olduğunda en küçük kareler (EKK) tekniği yetersiz kalmaktadır. Bağımlı değişken sınıflama düzeyinde olduğunda EKK tekniğine alternatif olarak kullanılabilecek tekniklerden birisi lojistik regresyon analizidir (Kalayc1, 2010).

Mertler ve Vannatta (2005)'a göre Lojistik regresyon analizinin temel odağ grubun üyesi olduğunu kestirmede kullanılacak bir regresyon eşitliği denklemi oluşturmaktır. Lojistik regresyon analizindeki amaç ise, kategorik bağımlı değişkenin değerini tahmin etmek olduğundan, aslında burada yapılmaya çalışılan iki ya da daha fazla gruba ilişkin "üyelik" tahminidir (Akt: Çokluk, Şekercioğlu ve Büyüköztürk, 2012)

İncelenen birey sayısı, $\mathrm{n}$; açıklayıcı değişken vektörü, $\mathrm{Y}=(\mathrm{Y} 1, \mathrm{Y} 2, \ldots, \mathrm{Yn})^{\prime}$ parametre vektörü, $\beta=\left(\beta 0, \beta 1, \ldots, \beta n\right.$; hata terimleri vektörü, $\varepsilon=(\varepsilon 1, \varepsilon 2, \ldots, \varepsilon n)^{\prime}$ olduğunda açılklayıcı değişken sayısı p olmak üzere, sabit terimin bulunduğu bir model için açıklayıcı değişkenler matrisi X ile gösterilsin. Bu durumda açıklayıcı değişken matrisi (1)'de verildiği gibidir.

$$
\mathrm{X}=\left|\begin{array}{ccccc}
1 & X_{1,1} & X_{2,1} & \ldots & X_{p, 1} \\
1 & X_{1,2} & X_{2,2} & \ldots & X_{p, 2} \\
\cdot & \cdot & \cdot & \ldots & \cdot \\
\cdot & \cdot & \cdot & \ldots & \cdot \\
\cdot & \cdot & \cdot & \ldots & \cdot \\
1 & X_{1, p} & X_{2, p} & \ldots & X_{p, n}
\end{array}\right|
$$

Açıklayıcı değişken matrisinde her bir sütun bir açıklayıcı değişkene ilişkin n tane gözlem değerinden oluşmaktadır. Bu durumda doğrusal regresyon modeli eşitlik-2'deki gibi gösterilebilir.

$$
\mathrm{Y} \quad=\quad \mathrm{X} \beta+\quad+\quad \varepsilon 1
$$

Lojistik regresyon analizinde (2) modelindeki regresyon denkleminden parametrelerini tahmin etmek yerine i p olasılıklarının (3)'te verilen lojistik dağılıma uyduğu varsayılır: 


$$
\mathrm{p}=\mathrm{G}(\mathrm{X} \beta)=\frac{e^{\mathrm{X} \beta}}{1+e^{\mathrm{X} \beta}}=\frac{1}{1+e^{-\mathrm{X} \beta}}
$$

(3)'da verilen haliyle $\beta$ 'nın tahminini elde etmek zordur. Bunun nedeni (3) denkleminin doğrusal olmamasıdır. Bu eşitlik doğrusallaştırıldığında (4) numaralı denklem elde edilir:

$$
\text { Lojit }_{i}=\operatorname{In}\left(\frac{p_{i}}{1-p_{i}}\right)=\operatorname{In}\left(e^{X_{i} \beta}\right)=X_{i} \beta
$$

Lojistik regresyon analizinde bağımlı değişken kategorik olmakla birlikte, bağımsız değişkenler sürekli, kategorik ya da ikili olabilir (Tabachnick ve Fidell, 2001). Araştırmada kullanılan değişkenlere değinecek olursak; bağımlı değişken kategorik olarak belirlenmiş 2012 PISA sonuçlarından elde edilen matematik okuryazarlığı seviyesi (OECD ortalaması altı / başarısız, OECD ortalaması üstü/ başarılı), bağımsız değişkenler ise matematik dersini dört gözle bekleme, matematik ilgisi, matematik öz algılama hızlı öğrenme, azim- çabuk pes etme, matematik ile ilgili okuma yapma, matematikten zevk alma, anne ve baba eğitim durumlarıdır. Bağımlı değişken olarak seçilen matematik başarısı aslında puan olarak sürekli bir değişken olmasına rağmen araştırma kapsamında bu değişken, PISA 2012 puan ortalaması 494 puanla karşılaştırılarak kategorik bir değişkene dönüştürülmüştür. Normal dağıllımdaki 0 ile -1 standart sapma dışında kalan ilk \% 16'lık kısımdaki puanlar "başarısız", normal dağı̆lımdaki 0 ile +1 standart sapmanın dışındaki puanların ortalamadan yüksek olan puanlar "başarılı" olarak sınıflandırılmıştır. Bu şekilde sürekli bir değişken kategorik hale getirilmiştir. Bunun nedeni yordayıcı değişkenlerin bağımlı değişken üzerinde $[-1,+1]$ standart sapma değerleri arasındaki puanların net bir sinıflamaya izin vermemesidir. Normal dağılımda 0 standart sapma değerine yakın olan daha düşük ve daha yüksek puanlar yordayıcı değişkenler için açıklanan varyansta etkili olmayacaktır. Bu değerler genel anlamda sınıflandırma yüzdesine kesin bir etki yapmamakla birlikte bu sınıflandırma yüzdesini aşağı çekme eğilimi göstermektedir. Bu nedenle bu -1 standart sapma değerinden düşük ve +1 standart sapma değerinden yüksek olan puanlarla lojistik regresyon analizi yapılmıştır.

\section{Lojistik Regresyonun Varsayımları}

\section{1-Kategorilerde yer alan birey sayısı/oranı:}

Ele alınan grupta yordayıcı değişkenlerin sayısına göre çok az sayıda birey varsa, bazı problemler ortaya çıkabilir.

\section{2-Bağımsız değişkenler arasında çoklu bağlantı (Multicollinearity) olmamalıdır.}

Lojistik regresyonda bağımsız değişkenler birbirleriyle ilişkili olmamalıdır. Eğer analize giren bağımsız değişkenler arasında çoklu bağlantı varsa bu sorunu devre dışı bırakabilmek için bir 
ya da daha fazla değişkenin modelden çıkarılması tavsiye edilir. Kategorik değişkenler arasında çoklu bağlantı olup olmadığını bulmak için çok yönlü frekans analizi yapılmıştır.

\section{3-Aykırı değerler olmamalıdır.}

Doğrusal regresyonda olduğu gibi, aykırı değerler sonucu önemli derecede etkileyebilir. Aykırı değerlerin belirlenmesi için standartlaştırılmış artıklara bakılmıştır. z değeri $>|3|$ olanlar aykırı değerdir. Yapılan analiz sonucu standartlaştırılmış artıkları -3 ten küçük olan veriler bulunmamıştır (Çokluk, Şekercioğlu ve Büyüköztürk, 2012).

\section{Bulgular}

$\mathrm{Bu}$ bölümde lojistik regresyon analizi sonucunda elde edilen çıtıların tablolarına ve yorumlanmasına ilişkin bilgiler verilmektedir.

Tablo I

Başlangıç Modeli Gözlemlenen Durum Öyküsü

\begin{tabular}{l|c|cc}
\hline \multicolumn{2}{c}{ Gözlemlenen Durum } & \multicolumn{2}{c}{ Kaysayllar } \\
\hline \multirow{2}{*}{ Adım 0 } & 1 & 660,446 & $-1,034$ \\
& 2 & 659,093 & $-1,141$ \\
& 3 & 659,092 & $-1,144$ \\
& 4 & 659,092 & $-1,144$ \\
\hline
\end{tabular}

Yukarıdaki tabloda başlangıç modeli için gözlemlenen durum öyküsü sunulmuştur. Tablo 1 incelendiğinde modelin -2LL değerinin 660,446 ile başladığı görülmektedir. Bu değer 2. ve 3. gözlemlerde azalmaktadır.

Tablo 2

Lojistik Regresyona Ilişkin IIlk Sınıflandırma Durumu

\begin{tabular}{|c|c|c|c|}
\hline \multirow[t]{2}{*}{ Gözlemlenen Durum } & \multicolumn{2}{|c|}{ Kestirilen Durum } & \multirow[t]{2}{*}{ Doğru Sınıflandırma Yüzdesi } \\
\hline & 494 puan altı & 494 ve 494 üzeri & \\
\hline 494 puan altı & \multirow{2}{*}{$\begin{array}{l}452 \\
144\end{array}$} & \multirow{2}{*}{$\begin{array}{l}0 \\
0\end{array}$} & 100 \\
\hline 494 ve 494 üzeri & & & 0 \\
\hline \multicolumn{3}{|c|}{ Toplam Doğru Sınıflandırma Yüzdesi } & 75,8 \\
\hline
\end{tabular}


Araştırma kapsamında PISA matematik ortalamasının (494) -1 standart sapmanın altında kalanlar başarısız, ortalamanın +1 standart sapma üstünde kalanlara başarılı olarak iki kategoriye ayrılarak yapılan analiz sonucunda yukarıda verilen lojistik regresyona ait ilk sinıflandırma durumunda Türkiye verilerinin tümü sınıflandırıldığı ve doğru sınıflandırma yüzdesinin \%75,80 olduğu görülmektedir.

\section{Tablo 3}

Başlangıç Modelinde/Eşitlikte Yer Alan Değişkenler

\begin{tabular}{ccccccc}
\hline Adım 0 & B & Standart Hata & Wald & sd & p & Exp ( $\beta)$ \\
\hline Sabit & $-1,144$ & 0,096 & 241,001 & 1 & 0.00 & 0,319 \\
\hline
\end{tabular}

Tablo 3’te görüldüğü üzere, burada başlangıç modelini oluşturan ögeler yer almaktadır. Başlangıç modelde sabit değerin açıklanan varyans \%31,9 dur.

Tablo 4’te Blok 0’a ilişkin eşitlikte yer almayan değişkenler tablosu sunulmaktadır.

\section{Tablo 4}

Başlangıç Modelinde/ Eşitlikte Yer Almayan Değişkenler

\begin{tabular}{llccc}
\hline & Değişkenler & Puan & sd & P \\
\hline Adım 0 & Anne eğitim düzeyi & 132,554 & 1 &, 000 \\
& Baba eğitim düzeyi & 118,879 & 1 &, 000 \\
Matematik ile ilgili okuma yapma & 8,726 & 1 &, 003 \\
Matematik dersini dört gözle bekleme & 0,907 & 1 &, 341 \\
Matematikten zevk alma & 21,352 & 1 &, 000 \\
Matematik ilgisi & 4,07 & 1 &, 044 \\
Matematik öz algıllama/hızlı öğrenme & 53,903 & 1 &, 000 \\
Azim- çabuk pes etme & 57,45 & 1 &, 000 \\
Hata Ki-kare istatistiği $\left(X_{\beta 0}^{2}\right)$ & 211,031 & 8 &, 000 \\
\hline
\end{tabular}

Hata ki kare istatistiğinin modeldeki gibi anlamlı olması $\left(\mathrm{X} 2_{\beta 0}=211,031 \mathrm{p} \leq 0.05\right)$, modelde yer almayan yordayıcı değişkenlere ilişkin katsayıların, sıfırdan anlamlı derecede farklı olduğunu göstermektedir. Bu değişkenlerden bir ya da daha fazlasının modele eklenmesinin, modelin yordama gücünü arttıracağını göstermektedir. 
Tablo 5’te yordayıcı değişkenlerin modele girdiği durum için iterasyon öyküsü sunulmaktadır.

Tablo 5

Yordayı ı Değişkenlerin Modele Girdiği Durum için Gözlemlenen Durum Öyküsü

\begin{tabular}{|c|c|c|c|c|c|c|c|c|c|c|}
\hline \multicolumn{3}{|c|}{$\begin{array}{l}\text { Gözlemlenen } \\
\text { durum }\end{array}$} & \multicolumn{8}{|c|}{ Katsayılar } \\
\hline 貝 & $-2 \mathrm{LL}$ & 栉 & 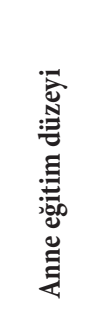 & 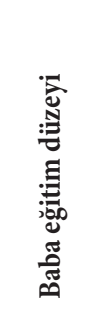 & 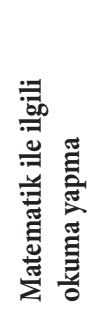 & 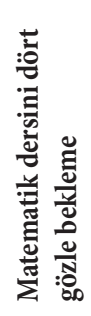 & 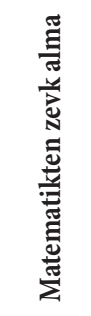 & 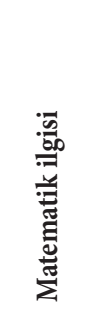 & 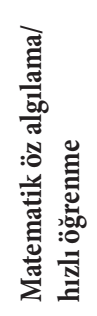 & 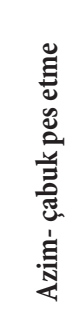 \\
\hline \multicolumn{11}{|l|}{1} \\
\hline & 471,826 & 0,908 & $-0,331$ & $-0,276$ & $-0,137$ & 0,315 & $-0,333$ & 0,164 & $-0,327$ & 0,241 \\
\hline 2 & 427,737 & 1,094 & $-0,441$ & $-0,435$ & $-0,26$ & 0,532 & $-0,517$ & 0,274 & $-0,537$ & 0,439 \\
\hline 3 & 422,155 & 1,092 & $-0,493$ & $-0,514$ & $-0,328$ & 0,646 & $-0,59$ & 0,314 & $-0,639$ & 0,557 \\
\hline 4 & 421,997 & 1,079 & $-0,503$ & $-0,529$ & $-0,342$ & 0,668 & $-0,601$ & 0,32 & $-0,659$ & 0,583 \\
\hline 5 & 421,997 & 1,078 & $-0,504$ & $-0,53$ & $-0,342$ & 0,669 & $-0,601$ & 0,32 & $-0,66$ & 0,584 \\
\hline
\end{tabular}

Tablo 6'da yordanan değişken ile yordayıcı değişkenler arasındaki ilişkinin varlığı Omnibus testi ile sunulmaktadır. Bir başka deyişle "sadece sabit terimin yer aldığı başlangıç modeli ile yordayıcı değişkenlerin analize girmesiyle oluşan amaçlanan model arasında fark yoktur" hipotezinin sinanması bu test ile yapılır.

Tablo 6

Model Katsayılarına Ilişkin Omnibus Testi

\begin{tabular}{ccccc}
\hline & & Ki-kare & sd & p \\
\hline Adım & Adım & 237,095 & 8 & 0.00 \\
& Blok & 237,095 & 8 & 0.00 \\
& Model & 237,095 & 8 & 0.00 \\
\hline
\end{tabular}

Yukarıdaki çıktıya göre başlangıç model ile amaçlanan model arasında anlamlı bir fark olduğu görülmektedir ( $\mathrm{p}<0.05)$. Dolayısıyla bağımsız değişkenler bağımlı değişken üzerinde anlamlı bir fark oluşturur. Eğer bu test anlamsız çıkarsa kurmaya çalıştığımız/amaçladığımız model arasında 
bir fark yoktur ve analize bu aşamadan sonra devam etmenin de gereği yoktur. Omnibus testi bir açıdan model veri uyumunu da gösterir.

\section{Tablo 7}

Amaçlanan Modelin Özeti

\begin{tabular}{cccc}
\hline Adım & $-2 \mathrm{LL}$ & Cox \& Snell $\mathrm{R}^{2}$ & Nagelkerke $\mathrm{R}^{2}$ \\
\hline 1 & 421,997 & 0,328 & 0,491 \\
\hline
\end{tabular}

Yordayıcı değişkenler analize girdiğinde yordanan değişkendeki varyansın ne kadarını açıkladığını Nagellerke $\mathrm{R}^{2}$ ve Cox\&Snell $\mathrm{R}^{2}$ ile açıklanmaktadır. Araştırmadaki model matematik çalışmadaki değişkenliğin \%49,1' ini açıklamaktadır.

\section{Tablo 8}

Hosmer ve Lemeshow Testi Sonucu

\begin{tabular}{cccc}
\hline Adım & Ki-kare & sd & p \\
\hline 1 & 5,112 & 8 & 0,495 \\
\hline
\end{tabular}

Lojistik regresyon sonuçlarında Hosmer ve Lemeshow Testi sonuçlarına yer verilmiştir. Ki-kare uyum iyiliği testi olarak ele alınan bu test, lojistik regresyon modelinin bir bütün olarak uyumunu değerlendirir. Bu teste ilişkin sonucun anlamlı olmaması ( $\mathrm{p}>0.05$ ) model veri uyumunun yeterli olduğunu gösterir. Bir başka ifadeyle "gözlenen ve model tarafından kestirilen değerler anlamlı fark yoktur" hipotezinin kabul edilmesi demektir ki bu da model tahminleri gözlenen durumdan farklı değildir; model, gözlenen durumla aynı tahmini yapar demektir. Bizim modelimiz için $\mathrm{p}=0.495>0.05$ olduğundan model veri uyumu sağlanmıştır.

\section{Tablo 9}

Lojistik Regresyon Modeli Sonucu Elde Edilen Sinıflandırma Tablosu

\begin{tabular}{c|l|cr|c}
\hline \multicolumn{2}{c}{ Gözlemlenen durum } & \multicolumn{2}{c}{ Kestirilen durum } & \multicolumn{2}{c}{ Doğru sinıflandırma yüzdesi } \\
\hline \multirow{3}{*}{ Adım 1 } & \multirow{2}{*}{494 puan altı } & 494 puan altı & 494 ve 494 üstü & \\
\cline { 3 - 4 } & 429 & 23 & 94,9 \\
& 494 ve 494 üstü & 65 & 79 & 54,9 \\
\hline \multicolumn{2}{c}{} & & 85,2 \\
\hline
\end{tabular}


Lojistik regresyon modeli sonucunda başarısız grubun doğru sınıflandırılma yüzdesi \%94,9 bulunurken, başarılı grubun doğru cevaplandırılma yüzdesi ise \%54,9 olarak bulunmuştur. Türkiye verilerinin tümü sınıflandırıldığında doğru sınıflandırma yüzdesinin $\% 85,2$ olduğu görülmektedir. İlk sınıflandırma ile karşılaştırıldığında doğru sınıflandırma yüzdesi \%75,8 iken bu değer lojistik regresyon sayesinde artmış ve \%85,2 olmuştur.

Tablo 10

Amaçlanan Model Değişkenlerinin Katsayı Tahminleri

\begin{tabular}{|c|c|c|c|c|c|c|c|}
\hline & & $\beta$ & $\begin{array}{c}\text { Standart } \\
\text { hata }\end{array}$ & Wald & df & $\mathrm{p}$ & $\operatorname{Exp}(\beta)$ \\
\hline \multirow[t]{9}{*}{ Adım 1} & Anne eğitim düzeyi & $-0,504$ & 0,112 & 20,163 & 1 & 0,00 & 0,604 \\
\hline & Baba eğitim düzeyi & $-0,530$ & 0,118 & 20,337 & 1 & 0,00 & 0,589 \\
\hline & Matematik ile ilgili okuma yapma & $-0,342$ & 0,186 & 3,387 & 1 & 0,066 & 0,710 \\
\hline & Matematik dersini dört gözle bekleme & 0,669 & 0,225 & 8,85 & 1 & 0,003 & 1,952 \\
\hline & Matematikten zevk alma & $-0,601$ & 0,247 & 5,939 & 1 & 0,015 & 0,548 \\
\hline & Matematik ilgisi & 0,320 & 0,210 & 2,325 & 1 & 0,127 & 1,377 \\
\hline & Matematik öz algılama/hızlı öğrenme & $-0,660$ & 0,189 & 12,214 & 1 & 0,00 & 0,514 \\
\hline & Azim- çabuk pes etme & 0,584 & 0,108 & 29,489 & 1 & 0,00 & 1,794 \\
\hline & Sabit & 1,078 & 0,645 & 2,794 & 1 & 0,045 & 2,939 \\
\hline
\end{tabular}

Analizin en son olarak verdiği tablo ise amaçlanan model değişkenlerinin katsayı tahminleridir. Tabloya göre matematik okuryazarlı̆̆ının sınıflandırılmasında anne eğitim düzeyi, baba eğitim düzeyi, matematik dersini dört gözle bekleme, matematikten zevk alma, matematik öz algılama/hızlı öğrenme, Azim- çabuk pes etme bağımsız değişkenlerin anlamlı etkisi olduğu görülmektedir. Anıl (2009) çalışmasında anne ve babanın eğitim düzeyi fen okuryazarlığı ile manidar pozitif ilişki verdiğini bulmuştur. Benzer şekilde Alomar (2006) ebeveynlerin eğitim düzeyinin başarı üzerinde dolaylı etkisinin olduğunu bulmuştur. Bu bulgular araştırma sonuçlarını desteklemektedir.

Tabloda her bir bağımsız (yordayıcı) değişken için lojistik regresyon katsayılarının anlamlılığını test etmede yaygın olarak kullanılan Wald istatistiğinin sonuçları ile verilmiştir. Çokluk (2010)'a göre Wald istatistiği standardize olmayan bir lojistik regresyonda $\beta$ katsayısının anlamlılık testine karşılık gelir. Tablodaki Wald değerleri, regresyon katsayısının standart hataya bölümünden sonra elde edilen değerin karesinin alınması ile hesaplanmıştır. 
Tabloda Exponentiated logistic coefficients $(\operatorname{Exp}(\beta))$ değerleri verilmiş, bu değerler üstel lojistik regresyon katsayılarıdır. Merter ve Vannata (2005)' e göre bu değerler her bir değişken için hesaplanan Odds oranıdır (Akt. Çokluk ve diğerleri, 2012) Yordayıcı değişkendeki bir birimlik değişmeden kaynaklı olarak Odds oranındaki meydana gelen değişmeleri göstermektedir. Exp ( $\beta$ ) değerleri şu şekilde yorumlanmıştır: Eğer değer 1'den büyükse, yordayıcı değişkendeki artışla birlikte, olayın olma ya da görülme olasılığına ilişkin Odds oranı yükselir. Eğer değer 1'den küçükse, yordayıcı değişkendeki artışa karşılık olayın olma ya da görülme olasılığı düşer (Field, 2005). Tabloyu yorumlayacak olursak; matematikte dersini dört gözle beklemedeki bir birimlik artış matematik okuryazarlığını 1,952 kat arttırmaktadır. Bir başka ifadeyle matematikteki azim arttıkça matematik okuryazarlığı puanı da artar. Aynı şekilde, matematik okuryazarlığını arttıran değişkenler sırasıyla matematik öz algılama/hızlı öğrenmedir. Matematik ile ilgili okuma yapıp-yapmama ve matematik ilgisinin matematik okuryazarlığı üzerinde anlamlı etkiye sahip değildirler.

\section{Sonuç ve Öneriler}

Bu çalışmada "matematik dersini dört gözle bekleme, matematikten zevk alma, matematik ilgisi, sebat boyutunda çabuk pes etme, hızlı öğrenme, matematikle ilgili okuma yapma, anne ve baba eğitim durumu” değişkenleri "matematik okuryazarlığının” değişkeninin anlamlı bir yordayıcısı olup olmadığı lojistik regresyon analizi ile incelenmiştir.

Verilerin analizi sonucunda matematik okuryazarlığının sınıflandırılmasında anne eğitim düzeyi, baba eğitim düzeyi, matematik dersini dört gözle bekleme, matematikten zevk alma, matematik öz algılama/hızlı öğrenme, azim- çabuk pes etme bağımsız değişkenlerinin anlamlı etkisi olduğu görülmektedir. Anne ve babanın eğitim düzeyinin öğrenci başarısı üzerinde etkisi olduğu benzer araştırmalarda da ortaya konmuştur (Anıl, 2009; Alomar, 2006, Gürsakal, 2012). Düşük gelirli Afro-Amerikan ailelerin bir örneğinde, annelerin tamamladığı eğitim süresinin çocuklarının bilişsel becerileri ile pozitif yönde ilişkili olduğu bulunmuştur (Murnane, 1981). Benzer şekilde Teachman (1987) ebeveyn eğitimi, aile geliri vb. sosyo-ekonomik göstergelerle ölçülen aile arka planının eğitime erişimde etkin rol oynadığının birçok araştırmada ortaya konduğunu belirtmiştir. Bu durumda anne ve babaların eğitim düzeyinin yükseltilmesi için gerekli çalışmalar yapılmalıdır. Birgin, Baloğlu, Çatlığlu ve Gürbüz (2010) araştırmalarında düşük düzey algılanan matematikten zevk almanın, algılanan ebeveynlerin matematiğe yardım düzeyinin ve başarı düzeyinin, yüksek düzey matematik kaygısına yol açtığını bulmuşlardır. Chiu ve Xihua (2008) 41 ülke verileriyle yaptıkları analizlerde çoğu ülkeden elde ettiği bulgularda PISA matematik bilişsel testinde azim ve çabanın daha yüksek puanlar almaya sebep olduğunu ortaya koymuşlardır.

Matematikle ilgili okuma yapıp-yapmama ve matematik ilgisinin düzeyinin matematik okuryazarlığı üzerinde anlamlı etkiye sahip değildirler. Bu sonuç Heinze, Reiss ve Franziska (2005)'in matematiğe olan ilginin, matematik başarısı için bir yordayıcısı olarak görülebilir şeklindeki bulgularıyla ve öğrencilerin matematik başarısı ve matematik ilgisi arasında bir 
ilişki olduğu ortaya koyan çalışmalarla (Uysal, 2015; Evans, Schweingruber ve Stevenson, 2002) örtüşmemektedir. Fisher, Dobbs-Oates, Doctoroff ve Arnold (2012) matematik ilgisi ile matematik yeteneği arasında karşılıklı bir ilişkinin okul öncesi eğitimde de mümkün olduğunu ortaya koymaktadır. Bunun yanında Marsh, Trautwein, Lüdtke, Köller, ve Baumert (2005) matematik ilgisi ile matematik başarısının arasında korelasyon olmasına rağmen, yapısal eşitlik modellemesindeki genel yapı modellerinde iki yapı arasındaki karşılıklı etkilerin desteklenmediğini vurgulamışlardır. Köller, Baumert ve Schnabel (2001) ise yapısal eşitlik modellemesiyle yaptıkları çalışmada matematik ilgisinin öğrenme üzerinde 7. sinıftan 10 . sınıfa kadar manidar bir etkisinin olmadığını bulmuşlardır ve ilginin çoğunlukla başarılı akademik öğrenmenin öncülü olarak düşünülmesine karşı çıkarak, boylamsal analizlere dayanan bulgularında bu varsayımının deneysel desteklerinin güçsüz olduğunu belirtip, başarı ile ilgi arasında manidar bir etki olmadığını yinelemişlerdir. İleride matematik ilgisi düzeyinin matematik okuryazarlığına etkisini araştıran başka çalışmalar da yapılabilir. .Elde edilen lojistik regresyon modelinde gözlemlerin doğru sınıflandırma oranlarının \%85,2 olduğu görülmektedir. Araştırma bulgularına göre matematik okuryazarlığında başarılı olan öğrencilerin \%94,9’u başarılı olmayan öğrencilerin ise $\% 54,9$ doğru olarak tahmin edilmiştir.

Araştırma bulguları neticesinde öğretmenlerin öğrencilerin matematiği dört gözle bekleyecek, matematikten zevk alacak şekilde öğrenme ortamlarının düzenlemesi önerilmektedir. Ayrıca araştırmalar PISA açık veri setinden matematik okuryazarlığı için farklı yordayıcılar ile lojistik regresyon modeli çalışılabilir. Bu çalışmada sadece istatistiksel teknik olarak lojistik regresyon modeli seçilmiştir. Elde edilen veriler ile lojistik regresyon modeli ile ayırma (diskriminant) analizi sonuçları karşılaştırılabilir. 


\section{Kaynaklar}

Ada, S. (2015). PISA 2012 Öğrenci Anketindeki Problem Çözme Göstergelerinin Farklı Ülkeler Açısından İncelenmesi. International Journal of Innovative Research in Education, 2(1), 32-38.

Anil, D. (2008). The Analysis of Factors Affecting the Mathematical Success of Turkish Students in the PISA 2006 Evaluation Program with Structural Equation Modeling. American-Eurasian Journal of Scientific Research, 3 (2): 222-227.

Anıl, D. (2009). Uluslararası Öğrenci Başarılarını Değerlendirme Programı (PISA)'nda Türkiye’deki Öğrencilerin Fen Bilimleri Başarılarını Etkileyen Faktörler. Eğitim ve Bilim, 34, 152: 87-100.

Alomar, B.O. (2006). Personel and Family Paths to Pupil Achievement. Social Behavior and Personality, 34 (8): 907-922.

Aydın, A., Erdağ, C. ve Taş, N. (2009). 2003 - 2006 PISA Okuma Becerileri Değerlendirme Sonuçlarının Karşılaştırmalı Olarak Değerlendirilmesi (Sınavda En Başarılı Beş OECD Ülkesi-Türkiye Örneği). Kuramda ve Uygulamada Eğitim Bilimleri Dergisi, 11(2): 651-673.

Balım, A. Evrekli, G, E. İnel, D. ve Deniş, H. (2009). Türki3ye’nin PISA 2006'daki Durumu Üzerine Bir İnceleme: Fen Bilimleri Yeterlilik Düzeyinin Bilgi ve İletişim Teknolojilerinin Kullanımına Göre Değerlendirilmesi. E-Journal of New World Sciences Academy. 4(3), 1053-1066.

Berberoğlu, G. ve Kalender, İ. (2005). Öğrenci Başarısının Yıllara, Okul Türlerine, Bölgelere Göre İncelenmesi: ÖSS ve PISA Analizi. Eğitim Bilimleri ve Uygulama, 4(7), 21-35.

Birgin, O., Baloğlu, M., Çatlığlu, H., \& Gürbüz, R. (2010). An Investigation of Mathematics Anxiety Among Sixth Through Eighth Grade Students in Turkey. Learning and Individual Differences, 20(6), 654658.

Büyüköztürk, Ş., Kılıç Çakmak, E., Akgün, Ö.E., Karadeniz, Ş. ve Demirel, F. (2013). Bilimsel Araştırma Yöntemleri. (15. Baskı) Ankara: PegemA Yayıncılık.

Çokluk, Ö., Şekercioğlu, G. ve Büyüköztürk, Ş.(2012). Sosyal Bilimler için Çok Değgişkenli İstatistik SPSS ve LISREL Uygulamaları (2. Baskı). Ankara: PegemA Yayıncılık.

Ceylan, E. (2009). PISA 2006 Sonuçlarına Göre Türkiyede Fen Okuryazarlığında Düşük ve Yüksek Performans Gösteren Okullar Arasındaki Farklar. Yüzüncü Yıl Üniversitesi Eğitim Fakültesi Dergisi, 4(2): 55-75.

Chiu, M. M., \& Xihua, Z. (2008). Family and Motivation Effects on Mathematics Achievement: Analyses of Students in 41 Countries. Learning and Instruction, 18(4), 321-336.

Çiftçi, A. (2006). PISA 2003 Matematik Alt Testi Sonuçlarına Göre Türkiye’deki Öğrencilerin Başarılarını Etkileyen Bazı Faktörlerin İncelenmesi. Yayımlanmamış Yüksek Lisans Tezi. Hacettepe Üniversitesi, Sosyal Bilimler Enstitüsü, Ankara.

Çokluk, Ö. (2010). Lojistik Regresyon Analizi: Kavram ve Uygulama. Kuram ve Uygulamada Eğitim Bilimleri, 10 (3): 1357-1407.

Çokluk, Ö., Şekercioğlu, G. ve Büyüköztürk, Ş. (2012). Sosyal Bilimler İ̧̧in Çok Değişkenli İstatistik (2. Baskı). Ankara: PegemA Yayıncilık.

Evans, E. M., Schweingruber, H., \& Stevenson, H. W. (2002). Gender Differences in Interest and Knowledge Acquisition: The United States, Taiwan, and Japan. Sex roles, 47(3), 153-167.

Fraenkel, J. R., Wallen, N. E. ve Hyun, H. H. (2012). How to Design and Evaluate Research in Education (8th edt.). New York: McGram-Hill Companies.

Field, A. (2005). Discovering Statistics Using SPSS (2.nd ed.). London: Sage.

Fisher, P. H., Dobbs-Oates, J., Doctoroff, G. L., \& Arnold, D. H. (2012). Early Math Interest and the Development of Math Skills. Journal of Educational Psychology, 104(3), 673-681. 
Gürsakal, S. (2012). PISA 2009 Öğrenci Başarı Düzeylerini Etkileyen Faktörlerin Değerlendirilmesi. Süleyman Demirel Üniversitesi İktisadi ve İdari Bilimler Fakültesi Dergisi, 17 (1), 441-452.

Heinze, A., Reiss, K., \& Franziska, R. (2005). Mathematics Achievement and Interest in Mathematics From a Differential Perspective. ZDM Mathematics Education, 37(3), 212-220. doi:10.1007/s11858-0050011-7

Kalaycı, Ş. (2010). SPSS Uygulamalı Çok Değişkenli İstatistik Teknikleri (5. Baskı). Ankara: Asil Yayıncılık.

Koğar, H. (2015). PISA 2012 Matematik Okuryazarlığını Etkileyen Faktörlerin Aracılık Modeli ile İncelenmesi. Eğitim ve Bilim, 40(179), 45-55.

Köller, O., Baumert, J., \& Schnabel, K. (2001). Does Interest Matter? The Relationship Between Academic Interest and Achievement in Mathematics. Journal for Research in Mathematics Education, 32 (5), 448-470.

Marsh, H.W,, Trautwein, U., Lüdtke, O., Köller, O., Baumert, J. (2005). Academic Self-Concept, Interest, Grades, and Standardized Test Scores: Reciprocal Effects Models of Causal Ordering. Child Development, 76(2): 397-416.

Milli Eğitim Bakanlığı. [MEB]. (2013). PISA 2012 Uluslararası Öğrenci Değerlendirme Projesi, Ulusal Ön Rapor. Ankara: Eğitim Araştırma ve Geliştirme Dairesi Yayınları. Web: http://yegitek.meb.gov.tr/ meb_iys_dosyalar/2013_12/13053601_pisa2012_ulusal_n_raporu.pdf 09 Ocak 2014’te alınmıştır.

Milli Eğitim Bakanlığı. [MEB]. (2015). PISA 2012 Uluslararası Öğrenci Değerlendirme Projesi, Ulusal Nihai Rapor. Ankara: Eğitim Araştırma ve Geliştirme Dairesi Yayınları. Web: https://drive.google.com/ file/d/0B2wxMX5xMcnhaGtnV2x6YWsyY2c/view 12 Mayıs 2016 tarihinde alınmıştır.

Murnane, R. J. (1981). New Evidence on The Relationship Between Mother's Education and Children's Cognitive Skills. Economics of Education Review, 1(2), 245-252.

Satıcı, K. (2008). PISA 2003 Sinavlarına Göre Matematik Okuryazarlı̆̆ın Belirleyen Faktörler: Türkiye ve Hong Kong-Çin. Yayımlanmamış Yüksek Lisans Tezi. Balıkesir Üniversitesi, Fen Bilimleri Enstitüsü, Balıkesir.

Shin, J., Lee, H., and Kim, Y. (2009). Student and School Factors Affecting Mathematics Achievement: International Comparisons Between Korea, Japan and The USA. School Psychology International, 30(520), 520-537.

Teachman, J. D. (1987). Family Background, Educational Resources, and Educational Attainment. American Sociological Review, 52 (4), 548-557.

Tabachnick, B.G. ve Fidell, L.S. (2001). Using Multivariate Statistics (Third Edition). New York, USA.:Harper Collins College Publishers.

Uysal, S. (2015). Factors Affecting The Mathematics Achievement of Turkish Students in PISA 2012. Educational Research and Reviews, 10(12), 1670-1678.

Yılmaz, E.T. (2006). Uluslararası Öğrenci Değerlendirme Programı (PISA)'nın Türkiye’deki Öğrencilerin Matematik Başarılarını Etkileyen Faktörler, Yüksek Lisans Tezi. Hacettepe Üniversitesi, Sosyal Bilimler Enstitüsü, Eğitim Bilimleri Anabilim Dalı, Ankara.

Zhang, D. ve Liu, L. (2016). How Does ICT Use Influence Students' Achievements in Math and Science Over Time? Evidence from PISA 2000 to 2012. Eurasia Journal of Mathematics, Science \& Technology Education, 12(9), 2431-2449. 